\title{
Innovative Design and Realization of a Smart Rotary Composter with a Remote Management System
}

\author{
Mustafa Elalami ${ }^{1}$, Mohamed Marouane Lahmadi ${ }^{2}$, Fatima Zahra Siti ${ }^{3}$, Yassine Baskoun ${ }^{4}$, Moha Arouch $^{5}$, \\ Fatima Zahra Beraich ${ }^{6}$ \\ 1, 3, 4, 5, 6 Laboratory of Engineering, Industrial Management and Innovation, Faculty of Sciences and \\ Technology, Hassan 1st University, Settat 26000, Morocco, mustafa.elalami@gmail.com \\ ${ }^{2}$ Arab German academy for science and technology ADAWT Engelsberg 7, Moers 47443, Deutschland \\ Lahmadi.mr@gmail.com
}

\begin{abstract}
This article describes the importance of using the most efficient and quickest means to treat organic waste, in this work we presented the design and realization of an automated machine that produces compost for 4 weeks with the reduction of $80 \%$ of the products per day in the city, in fact this technique will be an effective tool for provincial managers, and can be used on a small or large scale. As well as the remote control technique based on the communication between the remote database MySQL and the arduino UNO card and wifi module EPS8266, this exchange allows to control all the parameters of the composting process through a web application that presents these data in different forms, therefore the handling of the composter becomes more and more efficient and easy.
\end{abstract}

Key words : Design smart, rotary composting, remote control, database, web server

\section{INTRODUCTION}

In Morocco, as in all developing countries, land filling is the most commonly used method because of its lower cost and simplicity. However $75 \%$ of the organic matter is found in the large amounts of waste that occur daily.

Therefore, one of the primary causes for global warming is the spread of carbon dioxide and methane biogas, which are generated due to the natural decomposition of organic waste in landfills in the absence of oxygen levels. This leads to the production of the leachate flow that negatively influences water tables.

To solve this problem, there are many waste treatment techniques, among them composting, which is considered the best method because of its advantages, which allows the recycling of organic waste into better quality fertilizers [1], [2].Composting is the best solution to reduce the negative effects that result from the propagation of organic waste on soils by transforming organic waste into mature compost, using the degradation fields of macro- and micro-organisms.
Indeed this method is commonly used to produce organic fertilizers from organic waste that is rich in mineral compounds such as nitrogen, phosphorus and potassium [3]. Among the physico-chemical factors that impact the composting process are aeration, temperature, humidity and particle size. Composting is a heterogeneous and biochemical process based on the mineralization of carbon dioxide materials, Ammonia, Water with incomplete hydration to produce a stable product with reduced pathogenic toxicity [4],[5], the achievement of this process depends on good management, which relies on monitoring, control to obtain real-time information [6]-[7].

Therefore, a successful composting operation requires good $\mathrm{C} / \mathrm{N}$ (carbon/nitrogen content) mixing ratios, aeration rate [8], [9] to maintain the moisture content between $40 \%$ and $60 \%$ [10] and temperature control during the composting phases (mesophilic phase $\left(20^{\circ}\right.$ to $\left.45^{\circ}\right)$ and thermophilic phase $\left(45^{\circ}\right.$ to $\left.\left.65^{\circ}\right)\right)[11]$.

There are several methods of composting such as small-scale composting, compost pile which consists of putting the organic waste in an open air space, pile in container compost is used to put the waste in a closed container, barrel compost is used to put the organic waste in a rotating cylinder, trench compost is used to dig a hole in the ground and put the organic waste, worm compost is a decomposition process using various species of worms, white worms and other earthworms. Others of large scale such as aerobic windrow composting which consists of placing a mixture of raw materials in long narrow heaps that are stirred or turned regularly.

To speed up the composting process, if a rotating system with active aeration is used to reduce the composting time [11], [12],[13]. Previously, all composting parameters were monitored from time to time by humans. This leads to a delay in composting management and control, therefore the monitoring system has developed new technologies through the use of sensors. The compost heap was designed as a rotating cylinder with a temperature sensor, a moisture sensor and a mechanical rotation system to stir the compost [14]. After these techniques came into play. Today, the monitoring System applied to static composting has been designed with GSM/Bluetooth technology to monitor the process remotely. 
With the addition of new sensors, such as the gas sensor, to measure methane emissions [15], however, the application of these new techniques to rotary composting, which has huge advantages over static composting, remains a design challenge requiring several experiments on prototyping [16] and innovative technology transfer [17] as well as a remote application and control challenge based on the data collected with different sensors that are stored in a web application [18]-[19].The objective of this work is to design and manufacture a small-scale or large-scale continuous rotary drum composting machine with real-time monitoring and control of all composting parameters with odor reduction.

The structure of this work is as follows: The first section focuses on the operating principle, the design. The second section the control part of the system. The third section proposed system for the control part the last section results and discussions finally, a conclusion.

\section{DESIGN OF THE PROPOSED MACHINE THE COMPOSTING}

The continuous rotary drum composting system (1) Figure 2(A) is used to process food waste, agricultural waste and any organic waste by an aerobic composting process, completely mixed by the rotation of the drum and the steel sheets welded inside. The rotating drum is made of stainless steel sheet and supported by a support (2) with rollers (11) figure 2(C) it has a self-sealing door (12) figure 2(B) located on the longitudinal part of the drum which is used for the loading of solid organic waste. The discharge of the compost is continuous thanks to the conical shape on the right-hand side and the sheets welded on it.The introduction of homogeneous air into the drum is done by aeration which is carried out by means of a centrifugal fan (3) and perforated holes located on a round tube (5) figure 2(A).

The evacuation of the odor to the outside is carried out by the centrifugal fan with gain (7) and a carbon filter installed in the chimney in order to absorb this odor (8). The drum is guided in rotation by four rollers (11) figure 2(A) which rotate at a speed of (4 rpm) thanks to a $220 \mathrm{~V}$ electric motor, a helical gear reducer (9) figure 2(A) and a belt pulley system (10) figure 2(A).The temperature, humidity and $\mathrm{CH} 4$ methane content are controlled by the use of sensors (6) figure 2(A) which are installed on the round tube (5). Water is injected by a pump (4) if necessary, the collected data is processed using an Arduino UNO card installed in the control panel (13) figure 2(C) and transferred to a web server via the Wi-Fi module EPS8266

\section{CONTROL PART}

The system collects data (temperature, humidity, $\mathrm{CH} 4$ gas) from the rotary composter and sends it to a server via a Wi-Fi module (EPS 8266). After the data has been processed by the microcontroller (Arduino), this data is stored in the Cloud, which is accessible by the user figure 2 in order to visualize it

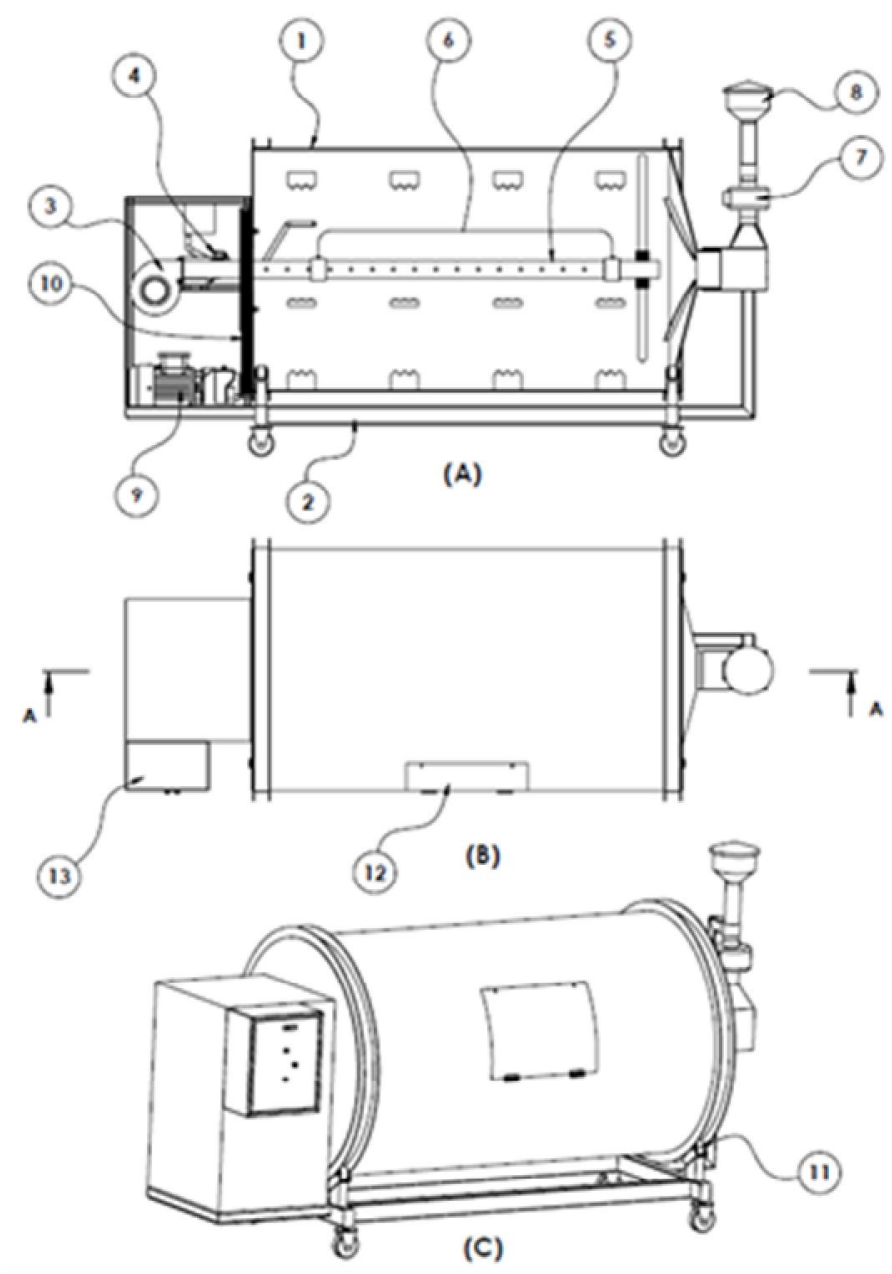

Figure 1: Assembly drawing of the rotating drum composting machine

in a timely manner, which can appear in the form of a table or graph. Below are the components used in the system.

\subsection{Temperature sensors}

For the measurement of the temperature in the drum (1) figure 2(A) we used two DS18B20 sensors installed in the round perforated type (11) of the machine it works on the 3 to $5.5 \mathrm{~V}$ dc. The temperature range $\left(-55^{\circ} \mathrm{C}\right.$ to $\left.+125^{\circ} \mathrm{C}\right)$. It is a 3-pin case with a single line it resists well in aggressive medium in denominators.

\subsection{Moisture sensors}

The humidity sensor has 6 pins, 2 of which are used for transmission and reception. Humidity sensors are useful for measuring compost moisture. If moisture measurements go below, appropriate measures can be taken. It has a long probe that dives inside the compost into the round perforated type (11) figure 2(A).the moisture content can be determined using the dielectric constant. The dielectric constant is calculated by the capacity of the electrode placed on the probe. It has a triple output mode that is analog and serial digital. 


\subsection{Gas sensor}

For measurement of methane emission, we can use the MQ GAS SENSOR that is MQ $2 \&$ MQ 4. MQ 2 has good sensitivity to methane and LPG, hydrogen and propane. It operates on voltage between $3.3-5 \mathrm{~V}$ it gets heated as its connected to power supply for a long time (48h) MQ 4 are 6 pin sensors the distributions of 6 pins are for fetching the signal. Two pins are for the current heating as it has low sensitivity to smoke and alcohol.

\subsection{Arduino UNO}

Arduino UNO has an Atmega328 microcontroller and 14 pins for digital input and output. On board, it has a USB connection port, a power outlet, a reset button, a $16 \mathrm{MHz}$ resonator. In addition to that, he also has SDA, SCL and AREF. It has 6 analog input pins. It also has a $14 \mathrm{~KB}$ flash memory. At digital pins 0 and 1, it has UART serial communication. The operating voltage of the Arduino is $5 \mathrm{~V}$. We can supply power by an adapter or by connecting a USB cable to the PC. We can program Arduino using Arduino IDE software. It has a SRAM of $2 \mathrm{~KB}$ and an EEPROM of $1 \mathrm{~KB}$.

\subsection{WI-FI Mod ESP8266}

The ESP8266 is a microcontroller with a WIFI card. It can therefore behave as a WIFI access point, and allow the user to connect directly to it from a connected device.

This component has a large storage and processing capacity powerful enough to be integrated with sensors and web applications.

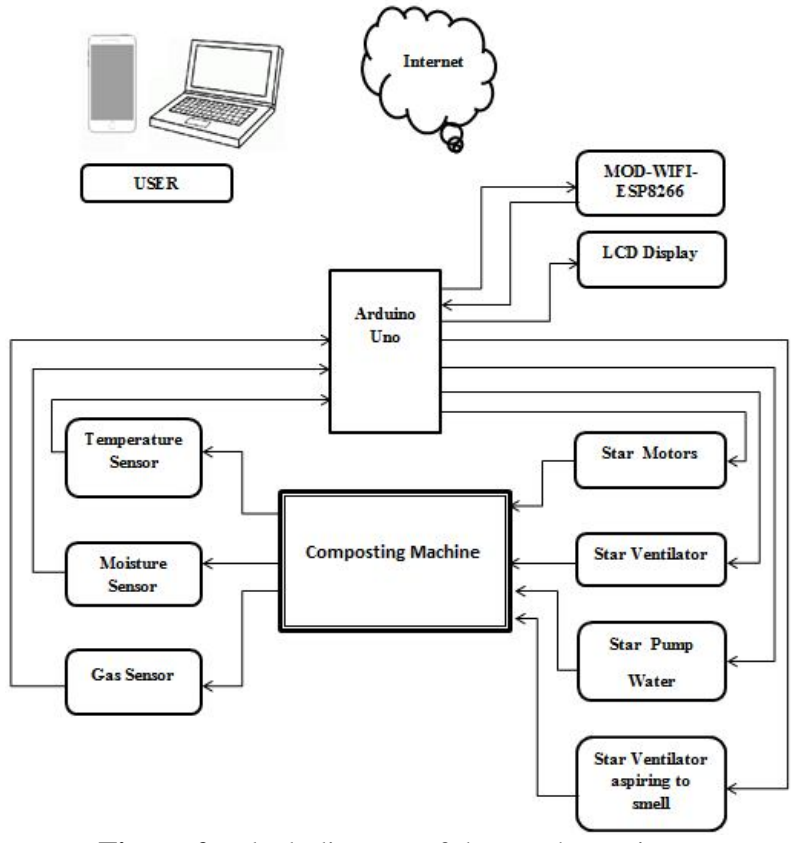

Figure 2: Block diagram of the Mechatronics system

\subsection{Web server}

Web server is created using HTML and PHP language. Web server is used to display the compost metrics on the web and to control the composting process remotely. We can create a web page or web app to serve data on database MySQL. The data transmission and reception can be done with the help of HTTP protocol.

\section{PROPOSED SYSTEM FOR THE CONTROL PART}

The proposed system monitors the composting process to form mature compost for 4 weeks. By using the monitoring system and the mechanical system Figure 2, we could make complete compost of nutrients with less methane emissions and less odor during the composting operation.

There are three main parameters of the compost, namely temperature, moisture content and oxygen content for aerobic composting. We can visualize these measurements acquired in real time on the web server.

The steps in monitoring the composting machine are as follows figure 3:

Step I: Power up, wait for the machine to initialize.

Step II: Waiting for the initialization of the sensors.

Step III: Monitor all parameters individually; check aeration conditions, humidity level and temperature level.

Step IV: If the humidity level drops by $40 \%$, automatically start water injection by a pump. When the humidity level exceeds $40 \%$, the water injection pump will be closed. If the humidity level exceeds $60 \%$, the fan will start.

Step V: If the temperature degree exceeds $60^{\circ}$, the water pump and fan aeration will be switched on to lower the temperature degree in the compost; if the temperature degree decreases by $20^{\circ}$, the hot air will be activated by the fan and the heating resistor installed downstream of the fan.

Step VI: if the aeration rate decreases, the blower fan will automatically turn on and the suction fan will be turned on to absorb the odor.

Step VII: After checking all the parameters, they will be displayed on the LCD screen.

Step VIII: All data is sent by arduino INO Wi-Fi ESP8266 to the server, this data will be displayed on the web application. Cycle stage: This stage consists of describing the machine's start-up cycle. After doing several practical experiments on the machine we have observed a cycle of 60 seconds of on and 540 seconds of off during the composting period.

\section{RESULTS AND TEST}

In order to validate the proposed continuous rotary composting machine as well as the control of composting parameters, we designed and manufactured an electromechanical system figure 4 based on field experiences during the classical composting process in collaboration with the Biodôme Company with the dimensions 


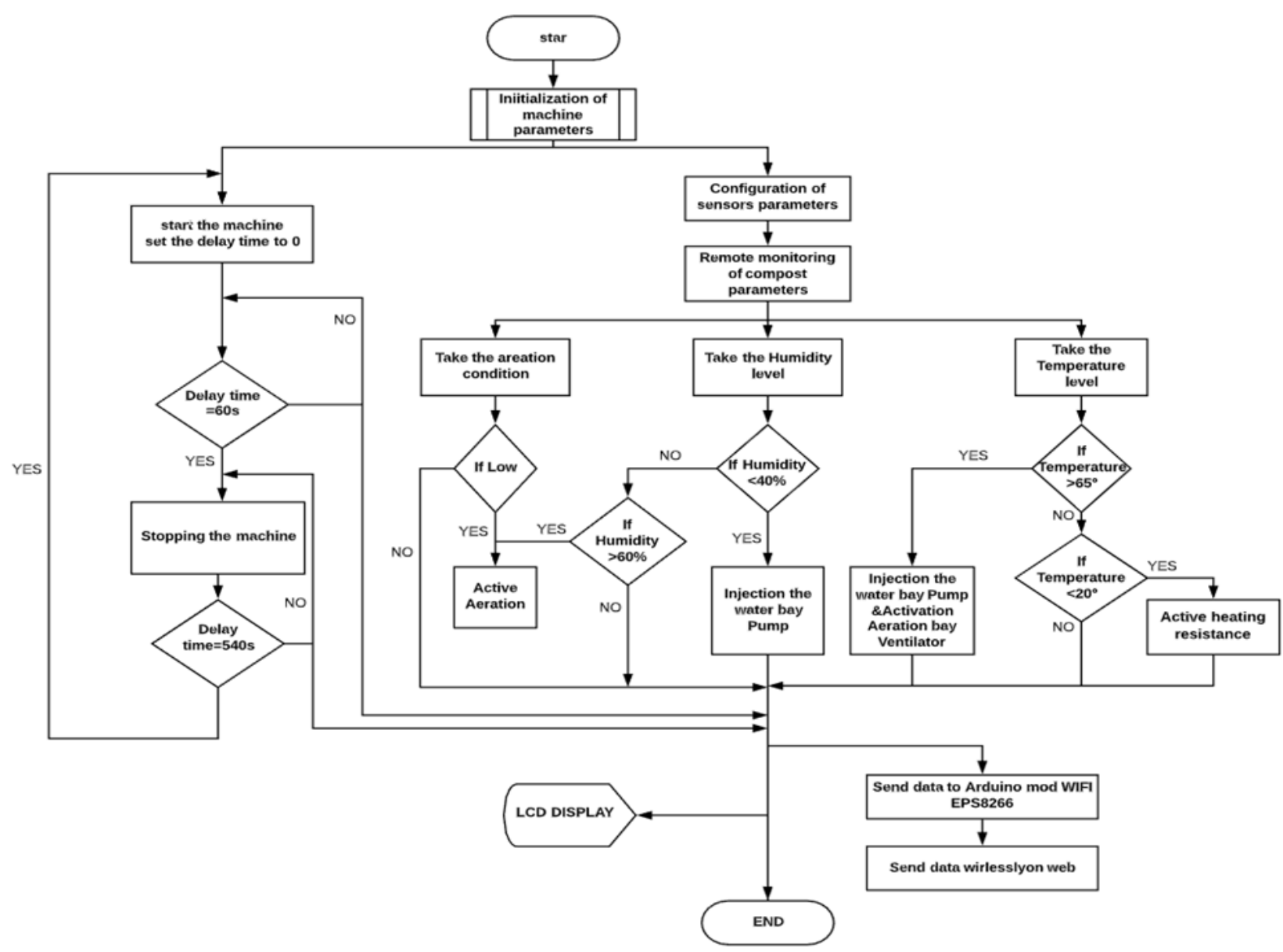

Figure 3: Flow Chart

(diameter $1 \mathrm{~m}$, length $2 \mathrm{~m}$, drum volume $1.5 \mathrm{~m}^{3}$ ), the composting process we have done to reach a composting duration of 4 weeks consists in reducing the size of the waste particles in a short time by a well-defined operating cycle of the machine ( $60 \mathrm{~s}$ of rotation and $540 \mathrm{~s}$ of stop for 24 hours) as well as the control of the composting parameter (aeration, temperature, humidity rate) in real time by a control circuit based on the above flowchart using Arduino Uno Atmega328 and sensors installed on the machine (MQ4 for methane, two DBS18B20 probes for temperature, two soil moisture sensors). For simulation purposes, we used the realization scheme shown in Figure 5 First, each sensor is. Simulated separately. After that, we combined all sensors and made the simulation. The results of the simulation are presented in figure 6 on the virtual terminal of the Arduino UNO (115200 bauds / COM3), the data sent to Arduino UNO are transferred to a MySQL database server figure 7(b) via the Wi-Fi module ESP8266, this database is communicated to a web application figure 7(a) to exploit these data in the form of graphs showing temperature statistics, moisture statistics and gas statistics, this application allows remote control of all the composting parameters in order to properly manage and control the machine.

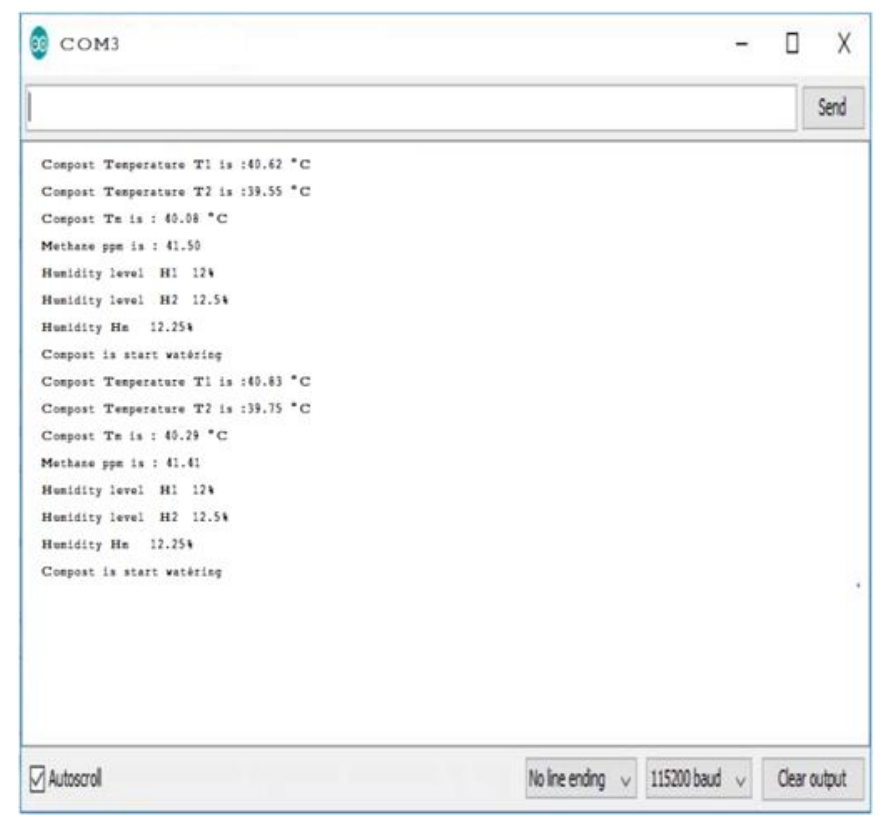

Figure 6:Simulation results displayed by virtual terminal 


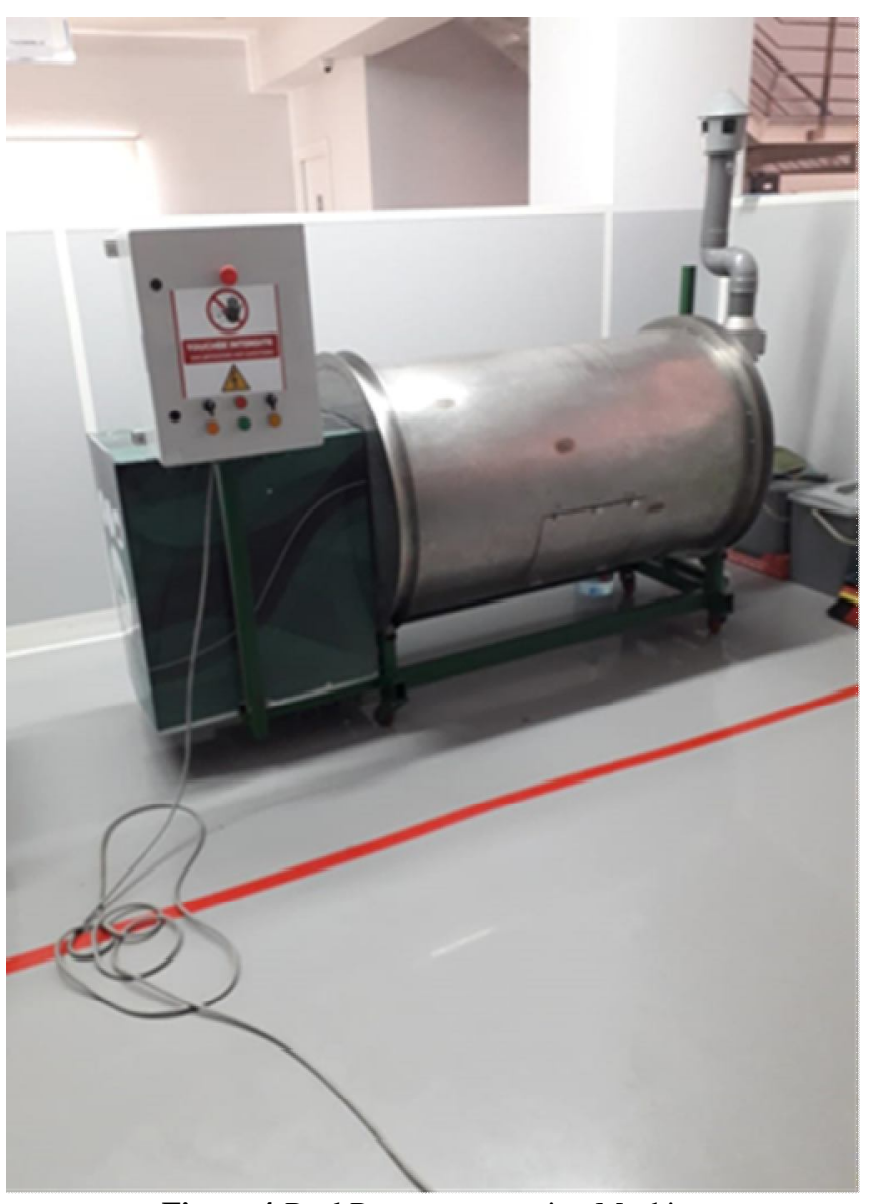

Figure 4:Real Rotary composting Machine

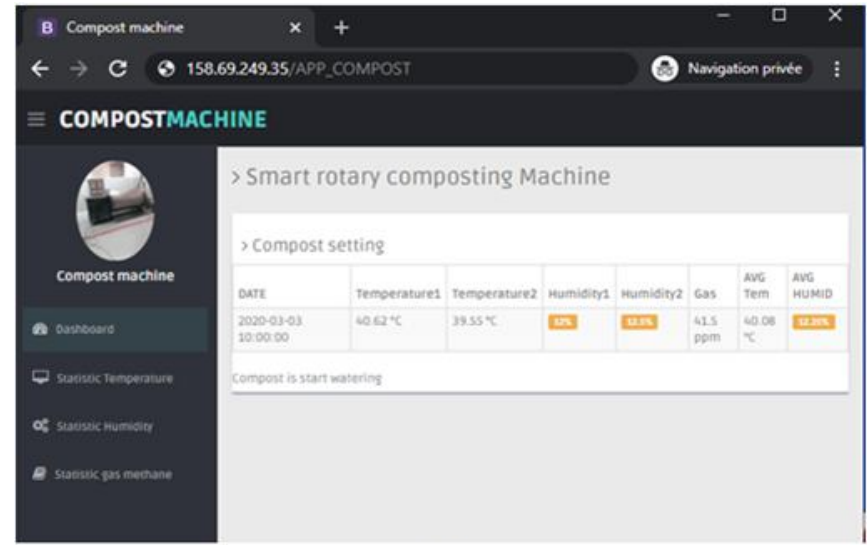

(a)

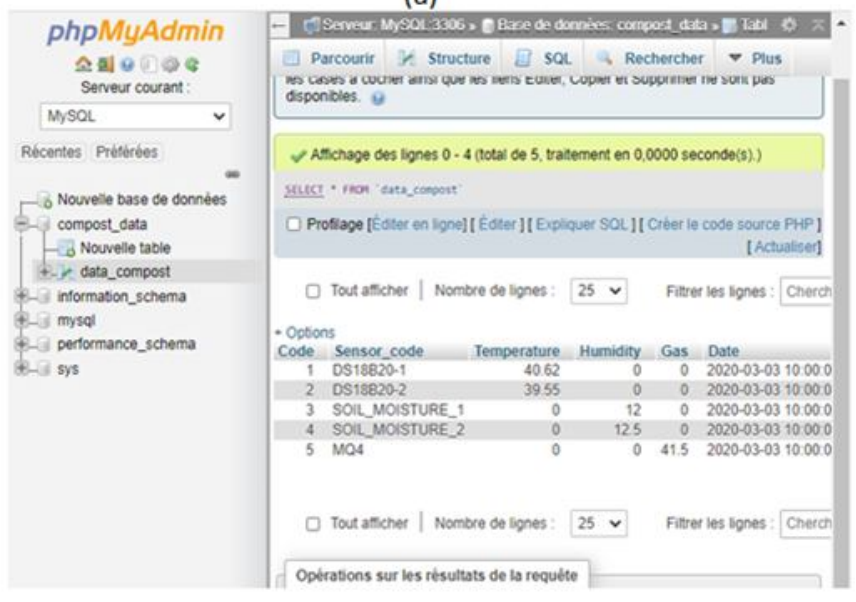

(b)

Figure 7:(a) web application, (b) database the web application

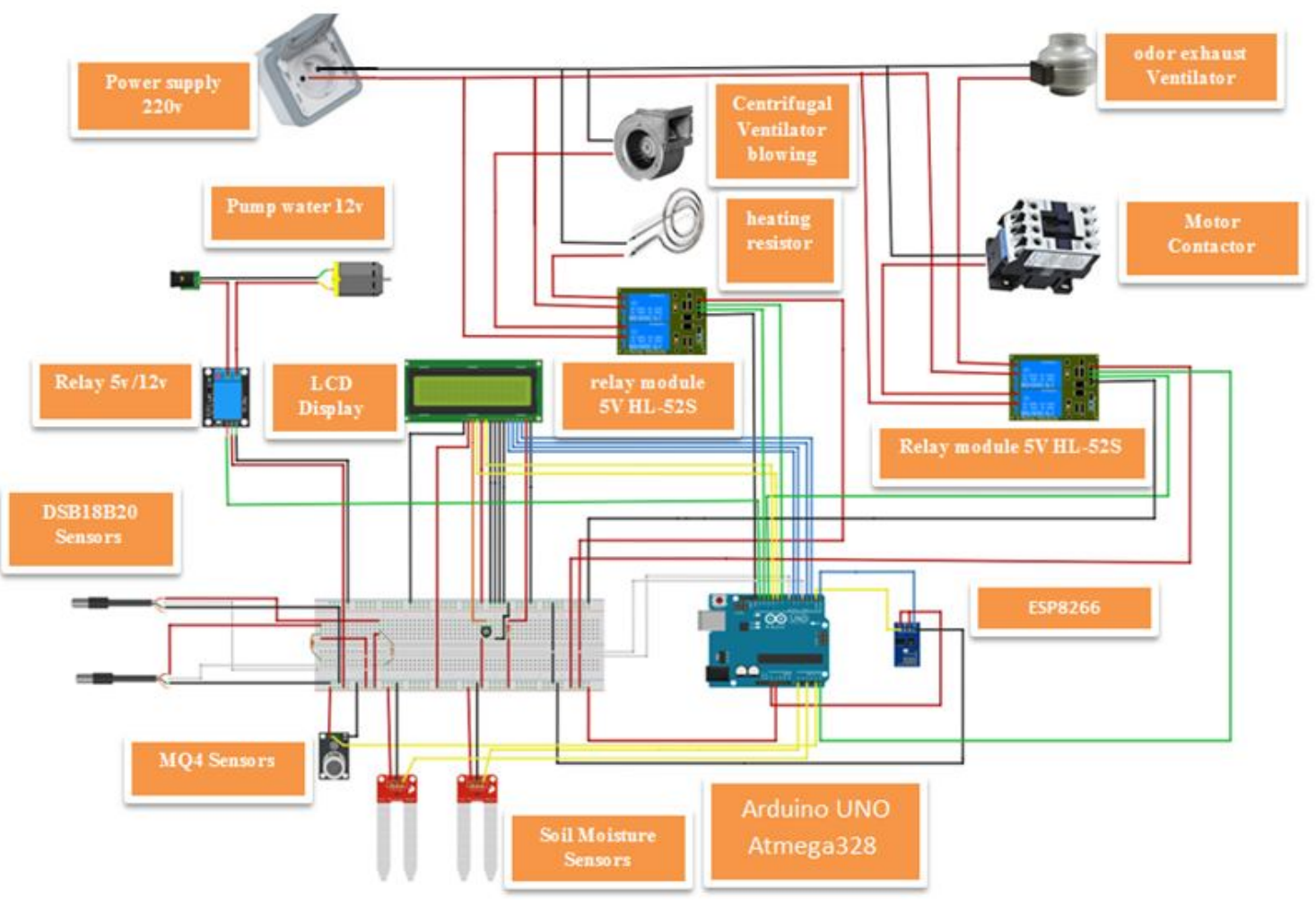

Figure 5:Scheme of realization and simulation 


\section{CONCLUSION}

This document reports on the study and design and implementation of an innovative rotating and continuous composter with the use of remote management techniques to provide real-time data to facilitate control and monitoring of the composter and ensure composting process parameters.

The use of this design, combined with the remote control technology, reduces the composting time to 4 weeks with less odors and thus produces mature compost.

The integration of remote control and monitoring into the composter requires the use of solid mechanical and electrical equipment, which presents a challenge in terms of mechanical, electrical and electronic design: first the placement of sensors in the rotary composter, then the measurement of humidity, temperature, and methane gas level, and then the communication between the composter and the remote database.

The solutions proposed in this article worked correctly, following the design specifications. The prototype is a better solution for managing, controlling and accelerating the composting process.

\section{ACKNOWLEDGEMENT}

Research leading to the above results received funding from the company BIODOME

\section{REFERENCES}

1. X. Qian, G. Shen, Z. Wang, C.Guo, Y.Liu,Z. Lei, and $Z$. Zhang. Co-composting of livestock manure with rice straw, Characterization and establishment of maturity evaluation system, Waste Manage, vol. 34, pp. 530-535, February2014.

2. I. Heribert, G.B. Maria, and A.J. Ascher. Recyling of organic Wastes to Soil and its Effet on Soil Organic Carbon Status, The Feature Of Soil Carbon,pp. 195-214, April 2018.

3. Y.Wang, P.Ai, H. Cao, and Z. Liu.Transformation of organic matters in animal wastes during,Bioresour. Technol, vol 193, pp. 200-205, December 2015.

4. M.F.D. Juarez, B. ahauser, A. Walter, A., Insam, and I.H. Franke-Whittle.Cocomposting of biowaste and wood ash, influence on a microbially driven-process, Waste Manage, vol 46, pp. 155-164, December 2015.

5. M. Das, H.S. Uppal, R.Singh, S.Beri, K.S. Mohan, V.C Gupta, and A. Adholeya .Co-composting of physic nut (Jatropha curcas) deoiled cake with rice straw and different animal dung, Bioresour. Technol, Vol. 102 (11), pp. 6541-6546, June 2011.

6. M.K. Awasthi, A.K. Pandey, J. Khan, P.S. Bundela, J.W.C. Wong, and A. Selvam.Cocomposting of gelatin industry sludge combined with organic fraction of municipal solid waste and poultry waste employing zeolite mixed with enriched nitrifying bacterial consortium. Bioresour. Technol, Bioresour. Technol, vol. 213, pp. 181-189, August 2016.
7. F. Storino, J.S. Arizmendiarrieta, I. Irigoyen, J.Muro, andP.M. Aparicio-Tejo. Meat waste as feedstock for home composting: effects on the process and quality of compost, Waste Manage, vol. 56, pp. 53-62, October 2016.

8. K. Kazemi, B. Zhang, L.M. Lye, Q. Cai, and T. Cao.Design of experiment (DOE) based screening of factors affecting municipal solid waste (MSW) composting,Waste mange, vol. 58, pp. 107-117, December 2016.

9. B. Zang, S. Li, F. Jr. Michel, G. Li, Y. Luo, D. Zhang, andY. Li. Effects of mix ratio, moisture content and aeration rate on sulfur odor emissions during pig manure composting, Waste Manage, vol. 56, pp. 498-505, December 2016.

10. United Nations Industrial Development Organization and Kingdom of Morocco. Compost de qualité Vers une agro-industrie durable au Maroc, Vienna, 2013, pp. 6.

11. F.N. Alkoaik.Integrating aeration and rotation processes to accelerate composting of agricultural residues, PLOS ONE 14(7): e0220343, July 2019.

12. F.Z.Beraich, M. Arouch, and M.Bakasse.composteur avec un reipient de compostage en forme de tambour,Morocco patent MA 37240 Al, july 2016.

13. M. Elalami, Y. Baskoun, F. Z. Beraich, M. Arouch, M. Taouzari, and S.D Qanadli.Design and Test of the Smart Composter Controlled by Sensors, 2019 7th International Renewable and Sustainable Energy Conference (IRSEC),Agadir,morocco,pp.1-6 https://doi.org/10.1109/IRSEC48032.2019.9078197

14. G. Vrettos, G. Kazamias, and D.F. Lekkas. Smart Compost Monitoring System using Open Source Technologies,15th International Conference on Environmental Science and Technology, Rhodes, Greece, 2017, pp. 1-6

15. G. E. Antonio, C.G. Arturo, and P. A.Carlos. design and construction of a composter for domestic use,CONIELECOMP 2011, 21st International Conference on Electrical Communications and Computers, San Andres Cholula, Mexico,2011,pp.1-5

16. Y. Baskoun, M. El Alami, S. D. Qanadli, M. Arouch and M. Taouzari.An Innovative Adapter to use Smartphone flashlight as a light source for endoscopy in emergency and LMICs, International Journal of Emerging Trends in Engineering Research, Vol.8, No.3, March 2020. https://doi.org/10.30534/ijeter/2020/33832020

17. O. ElyoussoufI Attou, S. Elganich, I, I. Taouaf, M. Arouchand B. Oulhadj.Modelization of the value chain for effective technology transfer within universities in Morocco,Journal of Advanced Trends in Computer Science and Engineering, Vol.8, No. 5, September-October, 2019 https://doi.org/10.30534/ijatcse/2019/03852019 
Mustafa Elalami et al., International Journal of Emerging Trends in Engineering Research, 8(7), July 2020, 3777 - 3783

18. G. Wang, N. Alamas and M. Anggraeni. The Use of Internet of Things and Big Data to Improve Customer Data in Insurance Company, International Journal of Emerging Trends in Engineering Research, Vol.7,No.12, December 2019.

https://doi.org/10.30534/ijeter/2019/047122019

19. . J. A. Basa, P. L. G. Cu , N. N. Malabag, L. A. V. Naag, D. F. P. Abacco, M. J. M. Siquihod, G. A. Madrigal , and L. K. S. Tolentino.Smart Inventory Management System for Photovoltaic-Powered Freezer Using Wireless Sensor Network,International Journal of Emerging Trends in Engineering Research,Vol.7,No.10, October 2019.

https://doi.org/10.30534/ijeter/2019/057102019 